University of Massachusetts Amherst

From the SelectedWorks of Peter Skott

2003

\title{
Distributional consequences of neutral shocks to economic activity in a model with efficiency wages and overeducation
}

Peter Skott, University of Massachusetts - Amherst 


\section{DEPARTMENT OF ECONOMICS}

\section{Working Paper}

Distributional consequences of neutral shocks to economic activity in a model with efficiency wages and overeducation

Peter Skott

Working Paper No. 2003-05

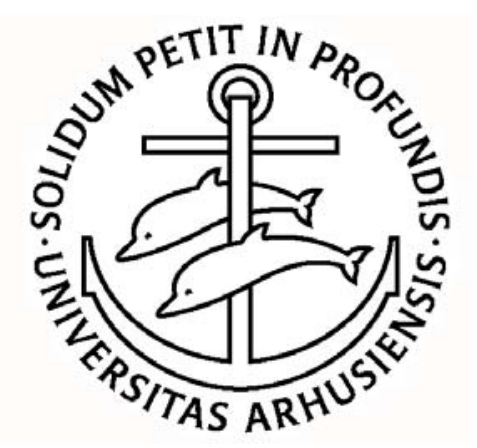

ISSN 1396-2426 


\title{
WORKING PAPER
}

Distributional consequences of neutral shocks to economic activity in a model with efficiency wages and overeducation

\author{
Peter Skott
}

Working Paper No. 2003-05 


\title{
Distributional consequences of neutral shocks to economic activity in a model with efficiency wages and overeducation *
}

\author{
Peter Skott ${ }^{\dagger}$
}

February 24, 2003

\begin{abstract}
This paper shows that the existence and persistence of 'overeducation' can be explained by a simple extension of the efficiency wage model. When calibrated to fit the amounts of overeducation found in most empirical studies, the model implies that both the relative wage and the relative employment rate of high-skill workers will depend inversely on the aggregate level of activity. The model may help explain the patterns of rising wage inequality that have been observed in many countries since the early 1970s.
\end{abstract}

Key words: Wage ineqality, overeducation, efficiency wages.

JEL classification: J31

*Some of the work for this paper was carried out while I was visiting the University of Massachusetts. Financial support from Aarhus Universitets Forskningsfond is gratefully acknowledged.

†Department of Economics, University of Aarhus, 8000 Aarhus C, Denmark. Email: pskott@econ.au.dk. 


\section{Introduction}

The purpose of this paper is twofold. It is shown, first, that the existence and persistence of 'overeducation' can be explained by a simple extension of the efficiency wage model. The model is used, second, to demonstrate that 'neutral' changes in aggregate economic activity will affect the distribution of wages.

A worker is overeducated if he has education in excess of that required to do his job. Qualifications are not necessarily the same as formal education and the measurement of overeducation involves many difficulties, both conceptual and empirical. ${ }^{1}$ There is strong evidence, however, that the incidence of overeducation is substantial. An influential study by Sicherman (1991) reports that 40 percent of US workers are overeducated, and Hersch (1991) finds overeducation figures ranging from 28 to 78 percent for different groups of workers in a sample from Oregon. In the UK, several studies indicate that about 30 percent of all respondents were overeducated and that the figure may be above 40 percent among those possessing more than the lowest level of qualifications (Sloane et al. (1999), Dolton and Vignoles (2000), Rigg et al (1990)). Summarizing the evidence, Green et al (1999, p.15) suggest that "overeducation is a widespread phenomenon both in Europe and the United States of America". ${ }^{2}$

Overeducation may emerge from efficiency wage models in a straightforward way. The presence of overeducation implies that workers with identical skills get different jobs. Some are lucky and get well-paid jobs that utilize their skills while others get less-skilled jobs with a lower pay. This asymmetry is similar to the asymmetries explained by other versions of efficiency wage models. A standard efficiency wage model explains why, in equilibrium, identical workers may have different employment status and different levels of income and utility. A multisectoral version of the model allows for the possibility that identical workers in different sectors may have different wages and utility levels. This paper shows how identical workers may be employed in the same firm but with different jobs and different wages and utility levels.

\footnotetext{
${ }^{1}$ Green et al (1999) and Hartog (2000) discuss some of the issues involved.

${ }^{2}$ See also Borghans and de Grip (2000) and the special issue on overeducation in Economics of Education Review (vol. 19, 2000).

Undereducation - workers who report having less education than required to get the job - also exists. Quantitatively, most studies indicate that about 10-20 percent of all workers are undereducated. The existence of undereducation on this scale could indicate 'credentialism': a change in the pool of applicants may lead employers to raise the skills required for recruitment to an otherwise unchanged job. Employers may prefer workers with the 'required education' but this level may not be needed to do the job. The formal model in this paper abstracts from both undereducation and credentialism.
} 
The formal model uses a shirking approach. The extension of the standard model lies in the introduction of two types of workers, high and low skill, and a distinction between the skill requirements of the job and the skills of the worker. Specifically, it is assumed that there is an asymmetry between the options of high- and low-skill workers. A high-skill worker who is unable to get a high-skill job may accept a low-skill wage in a low-skill job for which she is 'overeducated'. Low-skill workers do not have the analogous option of getting high-skill jobs. We thus get three no-shirking conditions: for high-skill workers in high-skill jobs, for high-skill workers in low-skill jobs and for low-skill workers in low-skill jobs. These no-shirking conditions are combined with labor demand curves derived from firms' profit maximization.

The position of the equilibrium may shift for a number of reasons, including shifts in the production function, changes in the degree of product market competition, or changes in the parameters that define the wage curves. This paper considers Hicks-neutral shifts in the demand for labor which leave the proportion of high-skill jobs constant if the relative wage rate is kept unchanged. In a standard model without overeducation, neutral shifts of this kind cannot simultaneously cause both the relative employment and the relative wage of low-skill workers to decline. Yet the empirical picture for both the US and the UK shows a dramatic decline in both relative employment and relative wages between the early 1970s and the mid 1990s, an observation which has been explained by a combination of skill-biases in technical progress, the effects of international competition and institutional changes in the labor markets. The model in this paper leaves out these possible influences. It demonstrates, instead, that 'induced overeducation' may have contributed to the observed changes: a negative, neutral shock to aggregate employment will raise unemployment among both low- and high-skill workers but since both groups of unemployed workers compete for low-skill jobs, the relative wage in low-skill jobs may come under pressure. As a result, one may see an increase in the proportion of low-skill jobs but a decrease in the proportion of low-skill workers in total employment. The increase in the proportion of low-skill jobs in turn implies a relative decline in low-skill wages. $^{3}$

The remainder of this paper is organized in three sections. Section 2 presents the model. The analysis of changes in aggregate labor demand is in section 3 , which also considers the effects of changes in relative labor supply. Section 4 contains a few concluding

\footnotetext{
${ }^{3}$ This type of (partial) explanation of the deterioration of both relative employment and relative wages for low-skill workers has been suggested by, among others, Thurow (1998) and Skott and Auerbach (2000).
} 
remarks. Proofs and derivations are collected in appendices 1-4.

\section{The model}

The economy is closed and produces a single output, Y. There are only two types of jobs, high and low skill, and two types of workers, high and low skill; a worker's skill level is observable. To simplify the exposition, non-labor inputs are disregarded. Thus, if there is no shirking,

$$
\begin{aligned}
Y & =A F\left(N_{H}, N_{L}\right) \\
F_{i} & >0, F_{i i}<0 \text { for } i=H, L, F\left(0, N_{L}\right)=F\left(N_{H}, 0\right)=0
\end{aligned}
$$

where $N_{H}$ and $N_{L}$ denote the number of high- and low-skill jobs that have been filled. All high-skill jobs are filled by high-skill workers while low-skill jobs may be filled by either low- or high-skill workers. Non-shirking high- and low-skill workers have the same productivity in low-skill jobs. The function $F$ satisfies the standard assumptions of constant returns and positive but diminishing marginal productivity of both inputs. ${ }^{4}$ To avoid the possibility of degenerate cases with only one type of job, it is assumed that both jobs are needed to produce a positive output.

The supplies of high- and low-skill workers are $H$ and $L$, respectively, and we have the following accounting relations:

$$
\begin{aligned}
H & =N_{H}+N_{H L}+U_{H} \\
L & =N_{L L}+U_{L} \\
N_{L} & =N_{L L}+N_{H L}
\end{aligned}
$$

where $U_{i}$ is unemployment among workers of type $i$ and $N_{L L}$ and $N_{H L}$ denote low- and high-skill workers in low-skill jobs; the number of high-skill workers in high-skill jobs is equal to the number of high-skill jobs $N_{H}$. The labour supplies $H$ and $L$ are fixed in most of the paper; section 3.3, however, considers the effects of changes in the relative supply of high-skill workers.

The wage structure is determined by efficiency wage considerations and, using a simple shirking setup (Shapiro and Stiglitz (1984)), employed workers either "shirk" or

\footnotetext{
${ }^{4}$ All results in this paper would go through if constant returns were replaced by the weaker assumption of homotheticity.
} 
"exert effort". Workers get instantaneous utility $u_{i j}$ given by

$$
u_{i j}=\begin{array}{cc}
w_{i j}-e_{i j} & \text { if employed and exerting effort } \\
w_{i j} & \text { if employed and shirking } \\
0 & \text { if unemployed }
\end{array}
$$

where $w$ and $e$ are wages and the costs in terms of utility of exerting effort; subscripts $i=H, L$ and $j=H, L$ denote the skills of the worker and the skill requirement of the job, respectively.

By assumption there are no low-skill workers in high-skill jobs and the skill levels are observable. Hence, there are three sets of no-shirking conditions, one for each group of employed workers. In a long-run equilibrium these conditions can be written:

$$
\begin{aligned}
\rho V_{H H} & =w_{H H}-e_{H H}-p\left(V_{H H}-V_{H U}\right)+q_{H H L}\left(V_{H L}-V_{H H}\right) \\
& =w_{H H}-(p+\delta)\left(V_{H H}-V_{H U}\right)+q_{H H L}\left(V_{H L}-V_{H H}\right) \\
\rho V_{H L} & =w_{H L}-e_{H L}-p\left(V_{H L}-V_{H U}\right)+q_{H L H}\left(V_{H H}-V_{H L}\right) \\
& =w_{H L}-(p+\delta)\left(V_{H L}-V_{H U}\right)+q_{H L H}\left(V_{H H}-V_{H L}\right) \\
\rho V_{L L}= & w_{L L}-e_{L L}-p\left(V_{L L}-V_{L U}\right)=w_{L L}-(p+\delta)\left(V_{L L}-V_{L U}\right)
\end{aligned}
$$

where

$$
\begin{gathered}
\rho V_{H U}=q_{H U H}\left(V_{H H}-V_{H U}\right)+q_{H U L}\left(V_{H L}-V_{H U}\right) \\
\rho V_{L U}=q_{L U L}\left(V_{L L}-V_{L U}\right)
\end{gathered}
$$

The variables $V_{i j}(i=H, L ; j=H, L, U)$ denote the present values of the future flows of utility for a worker of type $i$ with job status $j$. The parameters $\rho, p$ and $\delta$ are the discount rate, the exogenous rate of job terminations for non-shirking workers and the rate of detection for workers that shirk. ${ }^{5}$ While $\rho, p$ and $\delta$ are exogenously given, the values of the hiring rates $q$ are determined endogenously. Low-skill workers never get high-skill jobs and their hiring rates into low-skill jobs is $q_{L U L}$. Unemployed high-skill workers have hiring rates $q_{H U L}$ and $q_{H U H}$ into low- and high-skill jobs, respectively.

\footnotetext{
${ }^{5}$ One might expect the exogenous termination and detection rates, $p$ and $\delta$, to be higher for lowthan for high-skill jobs, while the discount rate $\rho$ may be higher for low- than for high-skill workers. The combined effects of these differences in the parameters on the no-shirking wages are ambiguous. Low rates of discount and exogenous termination reduce the no-shirking wage but this effect may be offset by a low detection rate. To simplify the analysis it is assumed, therefore, that the termination, detection and discount rates are the same across workers and jobs
} 
High-skill workers, finally, may move directly from a high- to a low-skill job (if low-skill jobs are the more attractive) or, alternatively, directly from a low- to a high-skill job (if high-skill jobs are more attractive). The transition rates for these direct moves are $q_{H H L}$ and $q_{H L H}$.

Straightforward manipulation of the no-shirking conditions yields

$$
\begin{aligned}
V_{H H}-V_{H U} & =\frac{e_{H H}}{\delta} \\
V_{H L}-V_{H U} & =\frac{e_{H L}}{\delta} \\
V_{L L}-V_{L U} & =\frac{e_{L L}}{\delta}
\end{aligned}
$$

Comparing (7) and (8) it follows that $V_{H H}-V_{H L}=\left(e_{H H}-e_{H L}\right) / \delta$. Thus, the relative magnitudes of the effort costs $e_{H H}$ and $e_{H L}$ will determine whether high-skill workers prefer low- or high-skill jobs. Theoretically, as well as empirically, the relevant scenario is one in which they prefer high-skill jobs. In the rest of this paper I shall therefore assume that $e_{H H}>e_{H L} \cdot{ }^{6}$ This assumption implies that no high-skill workers will want to move to a low-skill job. The transition rate $q_{H H L}$ will therefore be zero. Furthermore, all high-skill workers are identical and, when filling a high-skill job, firms will be indifferent between hiring an unemployed high-skill worker or a high-skill worker who is currently in a low-skill job. Both of these groups of workers want high-skill jobs, and I shall assume that they have the same hiring rates into high-skill jobs (that is, $q_{H U H}=q_{H L H}=q_{H H}$ ).

With these assumptions, the steady state conditions require that the hiring rates satisfy

$$
\begin{aligned}
p N_{H} & =q_{H H}\left(H-N_{H}\right) \\
p N_{H L}+q_{H H} N_{H L} & =q_{H U L}\left(H-N_{H}-N_{H L}\right) \\
p N_{L L} & =q_{L U L}\left(L-N_{L L}\right)
\end{aligned}
$$

or

$$
\begin{aligned}
q_{H H} & =\frac{p N_{H}}{H-N_{H}} \\
q_{H U L} & =\frac{\left(p+q_{H H}\right) N_{H L}}{H-N_{H}-N_{H L}}=p \frac{H}{H-N_{H}} \frac{N_{H L}}{H-N_{H}-N_{H L}} \\
q_{L U L} & =\frac{p N_{L L}}{L-N_{L L}}=p \frac{N_{L}-N_{H L}}{L-N_{L}+N_{H L}}
\end{aligned}
$$

\footnotetext{
${ }^{6}$ In a more disaggregate setup, high-skill workers need not have a relatively low utility cost of effort in all low-skill jobs. It is sufficient that for any particular skill there exist some low-skill jobs within the same area which a high-skill person, trained in that area, finds it relatively easy to perform.
} 
Using these expressions for the hiring rates, equations (2)-(9) can be used to derive the following wage equations:

$$
\begin{aligned}
w_{H H} & =e_{H L} \frac{p \frac{H}{H-N_{H}} \frac{N_{H L}}{H-N_{H}-N_{H L}}}{\delta}+e_{H H} \frac{\delta+\rho+p \frac{H}{H-N_{H}}}{\delta} \\
w_{H L} & =e_{H L} \frac{\delta+\rho+p \frac{H}{H-N_{H}-N_{H L}}}{\delta} \\
w_{L L} & =e_{L L} \frac{\delta+\rho+p \frac{L}{L-N_{L L}}}{\delta}
\end{aligned}
$$

By assumption, only high-skill workers have high-skill jobs, and the productivity of high- and low-skill workers is the same in low-skill jobs. Hence, if firms maximize profits, we must have

$$
\begin{aligned}
w_{H L} & =w_{L L}=w_{L} \text { if } N_{L L}>0 \text { and } N_{H L}>0 \\
w_{L L} & >w_{H L}=w_{L} \text { if } N_{H L}>0 \text { and } N_{L L}=0 \\
w_{H L} & >w_{L L}=w_{L} \text { if } N_{L L}>0 \text { and } N_{H L}=0 \\
w_{H H} & =w_{H}
\end{aligned}
$$

where $w_{H}$ and $w_{L}$ denote the wage rates for high and low-skill jobs. Note that, using (10)-(11), the assumption $e_{H H}>e_{H L}$ implies that $w_{H}>w_{H L}$.

\section{Wage effects of changes in aggregate employment}

\subsection{A case with induced overeducation}

At an interior solution the wage rates satisfy (10)-(13) and (16). Using (11)-(13), it follows that the unemployment rate for low-skill workers can be expressed as an increasing function of the unemployment rate for high-skill workers,

$$
u_{L}=\frac{u_{H}}{\frac{e_{H L}}{e_{L L}}+\frac{e_{H L}-e_{L L}}{e_{L L}} \frac{\delta+\rho}{p} u_{H}}
$$

where $u_{H}=\left(H-N_{H}-N_{H L}\right) / H$ and $u_{L}=\left(L-N_{L L}\right) / L$ are the unemployment rates for the two groups. Equation (17) implies that the unemployment rate for low-skill workers will exceed the unemployment rate for high-skill workers when $e_{H L}<e_{L L}$ (and that $u_{L}<u_{H}$ when $\left.e_{H L}>e_{L L}\right)$. The most interesting case - the one that would fit the empirical evidence of relatively low unemployment rates for high-skill workers - arises when the ratio $e_{H L} / e_{L L}$ is below one, and in what follows I shall focus on this case. 
If $n=N_{H}+N_{L}$ is total employment, equations (10)-(13) and (16) imply (see Appendix 1) that

$$
\frac{d \log \frac{w_{H}}{w_{L}}}{d \log n}=\operatorname{En}\left[B(x) \frac{N_{H}}{n} \frac{d \log N_{H}}{d \log n}-C(y) D(y, z)\right]
$$

where

$$
\begin{aligned}
x & =\frac{H}{H-N_{H}}=\frac{1}{u_{H}+\frac{N_{H L}}{H}} \\
y & =\frac{L}{L+N_{H L}-N_{L}}=\frac{1}{u_{L}} \\
z & =\frac{H}{H-N_{H}-N_{H L}}=\frac{1}{u_{H}} \\
B(x) & =\frac{\frac{L}{H} x^{2}}{\delta+\rho+p x}>0 \\
C(y) & =\frac{y^{2}}{\delta+\rho+p y}>0 \\
D(y, z) & =\frac{e_{H L} \frac{L}{H} z^{2}}{e_{H L} \frac{L}{H} z^{2}+e_{L L} y^{2}}>0 \\
E & =\frac{w_{H}-w_{L}}{w_{H}} p \frac{1}{L}>0 \text { for } e_{H H}>e_{H L}
\end{aligned}
$$

Profit maximization by firms gives another relation between changes in relative wages and relative factor inputs,

$$
d \log \frac{w_{H}}{w_{L}}=\eta\left(d \log N_{L}-d \log N_{H}\right)
$$

where $\eta$ is the inverse of the elasticity of substitution of the production function. From the definition of total employment, finally, we have

$$
d \log n=\theta d \log N_{H}+(1-\theta) d \log N_{L}
$$

where $\theta=N_{H} / n$. Combining (18)-(20), the effects of a change in aggregate employment on relative wages can be derived. ${ }^{7}$ We get (see Appendix 2)

$$
\frac{d \log \frac{w_{H}}{w_{L}}}{d \log n}=\eta \frac{n}{N_{L}}\left(1-\frac{d \log N_{H}}{d \log n}\right)
$$

\footnotetext{
${ }^{7}$ In terms of the model, the changes in aggregate employment may be generated by shifts in the multiplicative parameter $A$ in the production function (1). Hicks-neutral changes of this kind in the demand for labor leave the relation (19) between movements in relative wages and relative employment unchanged.
} 
where

$$
\frac{d \log N_{H}}{d \log n}=\frac{\eta+N_{L} E C(y) D(y, z)}{\eta+N_{L} E B(x) \frac{N_{H}}{n}}
$$

Using (21)-(22) we have the following result:

Proposition 1 If $e_{H H}>e_{H L}$ and $e_{L L}>e_{H L}$, high-skill workers will have higher wages and lower unemployment rates than low-skill workers at an interior equilibrium. In this case, furthermore, if $\Omega=N_{H L} /\left(N_{H}+N_{L}\right)$ denotes the degree of overeducation, the restriction $\Omega>\Omega^{\text {crit }}=u_{L} /\left(1+\left(1-u_{L}\right) \frac{L}{H}\right)$ is sufficient to ensure an inverse relation between the relative wage $w_{H} / w_{L}$ and aggregate employment.

Proof: See Appendix 3.

It follows from Proposition 1 that with an unemployment rate among low-skill workers of, say, 0.2 or lower, the wage ratio $w_{H} / w_{L}$ varies inversely with the aggregate rate of unemployment even if the degree of overeducation is far below the figure of 30-40 percent suggested by most studies.

The wage ratio $w_{H} / w_{L}$ does not capture wage inequality as it is usually measured. Standard measures of the skill premium focus on the ratio $w_{H A} / w_{L}$ where $w_{H A}=\frac{N_{H}}{N_{H}+N_{H L}} w_{H}+\frac{N_{H L}}{N_{H}+N_{H L}} w_{L}$ is the average wage of high-skill workers. Furthermore, there is within-group inequality among high-skill workers. This within-group inequality can be described by

$$
\begin{aligned}
\sigma & =\sqrt{\frac{N_{H}}{N_{H}+N_{H L}}\left(\frac{w_{H}-w_{H A}}{w_{H A}}\right)^{2}+\frac{N_{H L}}{N_{H}+N_{H L}}\left(\frac{w_{L}-w_{H A}}{w_{H A}}\right)^{2}} \\
& =\frac{w_{H A}-w_{L}}{w_{H A}} \sqrt{\frac{N_{H L}}{N_{H}}}
\end{aligned}
$$

These measures of between- and within-group inequality both depend on the rate of aggregate employment. We have the following result:

Proposition 2 Assuming that the conditions in Proposition 1 for $d \log \frac{w_{H}}{w_{L}} / d \log n$ to be negative are met,

- the relative wage $w_{H A} / w_{L}$ will vary directly with aggregate employment ( $d \log \frac{w_{H A}}{w_{L}} / d \log n>$ 0 ) if the two types of labor are perfect substitutes in production (if $\eta \rightarrow 0$ ). 
- depending on parameter values, the relation between the relative wage $w_{H A} / w_{L}$ and aggregate employment may be inverse or direct when the elasticity of substitution is finite.

- if the relation between the relative wage $w_{H A} / w_{L}$ and aggregate employment is inverse then within-group inequality $\sigma$ will also be inversely related to aggregate employment.

Proof: See Appendix 4.

\subsection{Numerical examples}

Proposition 2 fails to give unambiguous results for the relative wage $w_{H A} / w_{L}$. Numerical analysis, however, suggests an inverse relation between aggregate employment and inequality for plausible parameter values, unless the existing estimates of overeducation greatly exaggerate actual overeducation.

Table 1 gives the initial values of the two measures of the relative wage $\left(w_{H} / w_{L}\right.$ and $\left.w_{H A} / w_{L}\right)$ and the within-group dispersion among high-skill workers for different values of $e_{H L} / e_{L L}$ and $e_{H H} / e_{L L}$. The table is derived using equations (10)-(13) and (16). Tables $2-3$, based on equations (18) and (24)-(25), show the effects of changes in employment on overeducation and wage inequality. All tables use $\delta=1, \rho=0.1, p=0.2$ and $L=H{ }^{8}$ Most studies (e.g. Card et al. (1999)) suggest a relatively low elasticity of substitution between high- and low-skill jobs and the production function is assumed to be either Leontief (Table 2a) or Cobb-Douglas (Table 2b). ${ }^{9}$ The initial degree of overeducation and the initial unemployment rate for low-skill workers are 0.3 and 0.1 , respectively, in Tables 1-2; these initial values are changed to 0.1 and 0.2 in Table 3.

As indicated by Table 1, the relative wage of high-skill workers is decreasing in $e_{H L} / e_{L L}$ but increasing in $e_{H H} / e_{L L}$. The intuition is straightforward. An increase in $e_{H L} / e_{L L}$ tightens the no-shirking condition for high-skill workers in low-skill jobs and

\footnotetext{
${ }^{8}$ The value $p=0.2$ implies that just over 18 percent of all workers will lose (or choose to leave) their jobs within one period; $\delta=1$ implies that a shirking worker has a 63 percent probability of detection within one period.

${ }^{9}$ The parameters of the production function are determined so as to ensure that the initial employment and wage rates (derived from (10)-(13) and (16)) are consistent with profit maximisation. If $e_{H L}=0$ and $e_{H H}=e_{L L}=1$, for instance, the parameter assumptions and the initial values of overeducation and unemployment for low-skill workers in Table 2 imply that the production functions are given by $Y=\min \left\{\lambda_{H} N_{H}, \lambda_{L} N_{L}\right\}$ with $\lambda_{H} / \lambda_{L}=3.42$ in the Leontief case and $Y=N_{H}^{\alpha} N_{L}^{1-\alpha}$ with $\alpha=0.30$ in the Cobb-Douglas case.
} 
puts upward pressure on the relative wage for low-skill jobs; an increase in $e_{H H} / e_{L L}$, analogously, tightens the no-shirking condition for high-skill jobs and raises the high-skill wage premium. ${ }^{10}$

The wage premium obtained by high-skill workers in Table 1 is not due to a skill shortage. The high-skill wage is high because many high-skill workers get low-skill jobs. Thus, suppose that high-skill workers were precluded from low-skill jobs. Using the same parameter values, relative labor supplies and initial employment rate for low-skill workers as in Table 1, this preclusion implies that if $e_{H H}=e_{L L}$ and $e_{H L}=0$ then the initial employment rate and relative wage for high-skill workers would have been $N_{H} / H=0.26$ and $w_{H} / w_{L}=0.44$ in the Leontief case and $N_{H} / H=0.69$ and $w_{H} / w_{L}=0.56$ in the Cobb-Douglas case. Thus, without overeducation high-skill workers would have experienced lower employment and lower wage rates than low-skill workers.

Table 1: Wage inequality for different values of $e_{H L} / e_{L L}$ and $e_{H H} / e_{L L}$

\begin{tabular}{ccccccc}
\multicolumn{3}{c}{$\left(\delta=1, \rho=0.1, p=0.2 ; L=H ; \Omega=0.3, N_{L L} / L=0.9\right)$} \\
$e_{H L} / e_{L L}$ & $w_{H} / w_{L}$ & $w_{H A} / w_{L}$ & $\sigma$ & $w_{H} / w_{L}$ & $w_{H A} / w_{L}$ & $\sigma$ \\
0.0 & 1.47 & 1.20 & 0.19 & 1.93 & 1.40 & 0.33 \\
0.2 & 1.37 & 1.16 & 0.16 & 1.84 & 1.36 & 0.31 \\
0.4 & 1.28 & 1.12 & 0.12 & 1.74 & 1.31 & 0.28 \\
0.6 & 1.18 & 1.08 & 0.08 & 1.65 & 1.27 & 0.25 \\
0.8 & 1.09 & 1.04 & 0.04 & 1.55 & 1.23 & 0.22 \\
1.0 & 1.00 & 1.00 & 0.00 & 1.46 & 1.18 & 0.19
\end{tabular}

\footnotetext{
${ }^{10}$ There is full employment for high-skill workers if $e_{H L}=0$. If their cost of effort is zero, high-skill workers in low-skill jobs will never shirk. Hence, the 'wage curve' for workers in low-skill jobs becomes horizontal at $w_{L}=0$ until all high-skill workers have a job; further increases in output requires the use of low-skill workers and their no-shirking condition now determines the wage. It follows that when $w_{L}$ is positive, there is no open unemployment among high-skill workers if $e_{H L}=0$. Those that fail to get a high-skill job get a low-skill job instead, bumping out low-skill workers in the process.
} 
Table 2a: Effects of changes in aggregate employment on overeducation and wage inequality: The Leontief case.

\begin{tabular}{|c|c|c|c|c|}
\hline \multicolumn{5}{|c|}{$e_{H H} / e_{L L}=1$} \\
\hline$\frac{e_{H L}}{e_{L L}}$ & $\frac{d \Omega}{d \log n}$ & $\frac{d \log \left(w_{H} / w_{L}\right)}{d \log n}$ & $\frac{d \log \left(w_{H A} / w_{L}\right)}{d \log n}$ & $\frac{d \sigma}{d \log n}$ \\
\hline 0.0 & -0.53 & -3.85 & -1.86 & -1.95 \\
\hline 0.2 & -0.43 & -2.97 & -1.38 & -1.50 \\
\hline 0.4 & -0.33 & -2.11 & -0.95 & -1.06 \\
\hline 0.6 & -0.23 & -1.30 & -0.56 & -0.65 \\
\hline 0.8 & -0.11 & -0.59 & -0.24 & -0.29 \\
\hline 1.0 & 0.00 & 0.00 & 0.00 & 0.00 \\
\hline \multicolumn{5}{|c|}{$e_{H H} / e_{L L}=2$} \\
\hline$\overline{e_{L L}}$ & $\overline{d \log n}$ & $d \log n$ & $d \log n$ & $\overline{d \log n}$ \\
\hline 0.0 & -0.53 & -5.84 & -3.18 & -2.90 \\
\hline 0.2 & -0.43 & -4.98 & -2.66 & -2.49 \\
\hline 0.4 & -0.33 & -4.12 & -2.15 & -2.08 \\
\hline 0.6 & -0.23 & -3.28 & -1.68 & -1.66 \\
\hline 0.8 & -0.11 & -2.49 & -1.25 & -1.27 \\
\hline 1.0 & 0.00 & -1.78 & -0.88 & -0.91 \\
\hline
\end{tabular}


Table 2b: Effects of changes in aggregate employment on overeducation and wage inequality: The Cobb-Douglas case.

$\begin{array}{ccccc}\left(\delta=1, \rho=0.1, p=0.2 ; L=H ; \Omega=0.3, N_{L L} / L=0.9 ; \eta=1\right) \\ \frac{5}{5} e_{H H} / e_{L L}=1 \\ \frac{e_{H L}}{e_{L L}} & \frac{d \Omega}{d \log n} & \frac{d \log \left(w_{H} / w_{L}\right)}{d \log n} & \frac{d \log \left(w_{H A} / w_{L}\right)}{d \log n} & \frac{d \sigma}{d \log n} \\ 0.0 & -1.17 & -3.68 & -1.29 & -1.89 \\ 0.2 & -0.93 & -2.86 & -1.03 & -1.45 \\ 0.4 & -0.68 & -2.05 & -0.75 & -1.03 \\ 0.6 & -0.44 & -1.28 & -0.48 & -0.64 \\ 0.8 & -0.21 & -0.58 & -0.23 & -0.29 \\ 1.0 & 0.00 & 0.00 & 0.00 & 0.00 \\ & & e_{H H} / e_{L L}=2 & & \\ \frac{e_{H L}}{e_{L L}} & -d \Omega & \frac{d \log \left(w_{H} / w_{L}\right)}{d \log n} & \frac{d \log \left(w_{H A} / w_{L}\right)}{d \log n} & \frac{d \sigma}{d \log n} \\ 0.0 & -1.48 & -5.47 & -1.74 & -2.95 \\ 0.2 & -1.25 & -4.70 & -1.53 & -2.50 \\ 0.4 & -1.00 & -3.91 & -1.31 & -2.06 \\ 0.6 & -0.75 & -3.13 & -1.08 & -1.63 \\ 0.8 & -0.51 & -2.40 & -0.85 & -1.23 \\ 1.0 & -0.28 & -1.72 & -0.64 & -0.88\end{array}$

Turning to Tables 2a-2b, an increase in aggregate employment reduces both measures of the relative wage as long as $e_{H L} / e_{L L}$ is less than one. Thus, the numerical analysis suggests that when there is a substantial degree of overeducation, the elasticity of the relative wage $w_{H A} / w_{L}$ with respect to aggregate employment will be negative for a wide range of parameter values. From equation (17), furthermore, we have $\partial u_{L} / \partial u_{H}>1$ for $e_{H L} / e_{L L}<1$ and it follows that a rise in aggregate employment will benefit low-skill workers in terms of both relative wages and relative employment.

As shown by Proposition 1, the degree of overeducation in combination with the unemployment rate for low-skill workers can be critical for the relation between relative wages and aggregate employment, and measures of overeducation, in particular, are subject to considerable uncertainty. Table 3 presents the implications of assuming initial values of 0.1 and 0.2 for overeducation and low-skill unemployment, respectively. Even with these, less favorable assumptions an increase in aggregate employment will in almost all cases lead to a reduction in the average skill premium. The only exceptions arise when the production function is Cobb-Douglas and the ratio $e_{H L} / e_{L L}$ is below 0.4. 
Table 3: Effects of changes in aggregate employment on overeducation and wage inequality when initial rates of overeducation and low-skill employment are low

$\begin{array}{ccccc}\left(\delta=1, \rho=0.1, p=0.2 ; L=H ; e_{H H} / e_{L L}=2 ; \Omega=0.1, N_{L L} / L\right. \\ \text { Leontief } \\ \frac{e_{H L}}{e_{L L}} & \frac{d \Omega}{d \log n} & \frac{d \log \left(w_{H} / w_{L}\right)}{d \log n} & \frac{d \log \left(w_{H A} / w_{L}\right)}{d \log n} & \frac{d \sigma}{d \log n} \\ 0.0 & -0.56 & -1.35 & -0.63 & -0.93 \\ 0.2 & -0.50 & -1.34 & -0.71 & -0.83 \\ 0.4 & -0.42 & -1.26 & -0.73 & -0.70 \\ 0.6 & -0.31 & -1.09 & -0.69 & -0.54 \\ 0.8 & -0.17 & -0.85 & -0.61 & -0.35 \\ 1.0 & 0.00 & -0.58 & -0.50 & -0.16 \\ & & \text { Cobb-Douglas } & \\ \frac{e_{H L}}{e_{L L}} & \frac{d \Omega}{d \log n} & \frac{d \log \left(w_{H} / w_{L}\right)}{d \log n} & \frac{d \log \left(w_{H A} / w_{L}\right)}{d \log n} & \frac{d \sigma}{d \log n} \\ 0.0 & -0.74 & -0.73 & 0.20 & -1.12 \\ 0.2 & -0.69 & -0.80 & 0.06 & -1.02 \\ 0.4 & -0.62 & -0.82 & -0.08 & -0.89 \\ 0.6 & -0.50 & -0.79 & -0.20 & -0.71 \\ 0.8 & -0.34 & -0.68 & -0.28 & -0.49 \\ 1.0 & -0.12 & -0.50 & -0.32 & -0.24\end{array}$

\subsection{Sensitivity of wages to changes in relative supply}

The presence of overeducation affects the sensitivity of the relative wage to changes in the relative labor supply. Consider, for example, the implications of a change in the relative labor supply from $(H, L)=(1,1)$ to $(H, L)=(0.5,1.5)$ or to $(H, L)=(1.5,0.5)$. Using the parameter values in Tables 1 and 2 and assuming that the aggregate employment rate is kept constant, these massive changes in the skill composition are reflected in the degree of overeducation and, to a lesser extent, within-group inequality. But, as indicated in Table 4 , the wage ratio $w_{H} / w_{L}$ does not decline monotonically as the proportion of high-skill workers increases. In fact, a nine-fold increase from $H / L=1 / 3$ to $H / L=3$, raises this wage ratio. The average wage premium $w_{H A} / w_{L}$, and hence the incentives to enter a training programme, does decline, but the decline is modest and the wage premium is virtually the same for $H / L=3$ and $H / L=1$. These implications, moreover, are strikingly similar for the Leontief and Cobb-Douglas specifications. This similarity is 
closely related to the other findings: if the wage ratio $w_{H} / w_{L}$ (as determined by the nonshirking conditions) does not change much in the Leontief case where $N_{H} / N_{L}$ is fixed, firms will have little incentive to change their input proportions in the Cobb-Douglas case.

Table 4: Wage inequality for different values of the relative supply of labour

$$
\begin{array}{ccccc}
\left(\delta=1, \rho=0.1, p=0.2 ; e_{H H} / e_{L L}=1, e h l=0 ; n=0.95\right) \\
\text { Leontief case }\left(Y=A \min \left\{3.42 N_{H}, N_{L}\right\}\right) \\
H=0.5, L=1.5 & 0.04 & w_{H} / w_{L} & w_{H A} / w_{L} & \sigma \\
H=1, L=1 & 0.30 & 1.47 & 1.53 & 0.14 \\
H=1.5, L=0.5 & 0.56 & 1.66 & 1.20 & 0.19 \\
H & & & 0.25
\end{array}
$$

Cobb-Douglas case $\left(Y=A N_{H}^{0.3} N_{L}^{0.7}\right)$

$\begin{array}{ccccc}H=0.5, L=1.5 & \Omega & w_{H} / w_{L} & w_{H A} / w_{L} & \sigma \\ H=1, L=1 & 0.05 & 1.55 & 1.45 & 0.14 \\ H=1.5, L=0.5 & 0.30 & 1.47 & 1.20 & 0.19 \\ H & 0.58 & 1.65 & 1.17 & 0.24\end{array}$

\subsection{The case without overeducation}

A corner solution without overeducation $\left(N_{H L}=0\right)$ can be obtained if the value of $e_{H L} / e_{L L}$ is sufficiently high. ${ }^{11}{ }^{12}$ In this case high-skill workers will exert no effort when the wage rate satisfies the no-shirking condition for low-skill workers. Algebraically, we may have $e_{H L}\left(\delta+\rho+p \frac{H}{H-N_{H}-N_{H L}}\right)>e_{L L}\left(\delta+\rho+p \frac{L}{L-N_{L L}}\right)$ when $N_{H L}=0$ and

\footnotetext{
${ }^{11}$ Analogously, if $e_{H L} / e_{L L}$ is sufficiently low and the supply of high-skill workers is large (relative to total employment, $N_{H}+N_{L}$ ), we get a corner solution with $N_{L L}=0$.

${ }^{12} \mathrm{~A}$ solution with $N_{H L}=0$ may also obtain in the case where $e_{H L} / e_{H H} \geq 1$ if the supply of low-skill workers is sufficiently large. If high-skill workers find the effort associated with low-skill jobs more onerous than high-skill jobs then the no-shirking condition will require that they are paid a relatively high wage in low-skill jobs. If they were to be offered a low-skill job at this wage, they would be better off than in a high-skill job. If there are enough low-skill workers, however, the high value of the no-shirking wage $w_{H L}$ will mean simply that firms fill all low-skill jobs with low-skill workers, paying $w_{L L}<w_{H L}$.
} 
$\left(N_{H}, N_{L}\right)$ satisfy firms' first order conditions. That is, we may have

$$
\begin{aligned}
e_{H H} \frac{\delta+\rho+p \frac{H}{H-N_{H}}}{\delta} & =E F_{1}\left(N_{H}, N_{L}\right)=w_{H} \\
e_{H L}\left(\delta+\rho+p \frac{H}{H-N_{H}}\right) & >e_{L L} \frac{\delta+\rho+p \frac{L}{L-N_{L}}}{\delta}=E F_{2}\left(N_{H}, N_{L}\right)=w_{L}
\end{aligned}
$$

Now consider the effects of a change in aggregate employment in this "standard case" where all workers have the exact skills to match the requirements of their jobs. Using (19)-(20) and (23)-(24), straightforward calculations imply that

$$
\begin{aligned}
\frac{d \log \frac{w_{H}}{w_{L}}}{d \log n} & =\eta \frac{n}{N_{L}}\left[1-\frac{d \log N_{H}}{d \log n}\right] \\
& =\eta \frac{n}{N_{L}} \frac{(1-\theta)\left(h\left(\frac{H}{H-N_{H}}\right)-h\left(\frac{L}{L-N_{L}}\right)\right)}{\eta+(1-\theta) h\left(\frac{H}{H-N_{H}}\right)+\theta h\left(\frac{L}{L-N_{L}}\right)}
\end{aligned}
$$

where the function $h(x), x>1$, is defined by

$$
h(x)=\frac{x^{2}}{\delta+\rho+p x} \frac{x-1}{x} ; h>0, h^{\prime}>0 \text { for } x>1
$$

The function $h$ is increasing in the relevant range and it follows that the numerator of (25) is positive if and only if the employment rate for high-skill workers exceeds that for low-skill workers $\left(N_{H} / H>N_{L} / L\right)$. An increase in aggregate employment, in other words, will raise the relative wage of high-skill workers in the empirically relevant case where $N_{H} / H>N_{L} / L$. The reason is straightforward. With an unchanged relative wage, firms would choose the same proportional increase in employment for the two groups. This proportional increase in employment would cause a disproportionate decline in the unemployment rate for high-skill workers, who initially have the lowest unemployment rate, and, given the non-linearity of the wage equations (23)-(24), the relative wage for high-skill workers would have to rise. An increase in output, therefore, must lead to a rise in the relative employment of low-skill workers and a decline in their relative wage.

\section{Concluding remarks}

This paper has demonstrated, first, that the existence and persistence of overeducation can be explained by efficiency wage considerations. By construction, the relative supply of high-skill workers in the numerical examples in section 3.2 was such that had highskill workers been precluded from low-skill jobs, their wage would have fallen below 
that of low-skill workers. High-skill workers therefore had an incentive to seek lowskill employment, employers had an incentive to hire them, and the efficiency-wage equilibrium was characterized by a substantial wage premium to workers in high-skill jobs. This wage premium provides an incentive for workers to acquire the high skill, even though they face a risk of spending at least a part of their working life in low-skill jobs. Thus, there is no reason to expect overeducation to be eliminated by endogenous changes in the relative supply of high-skill labor. In fact, as shown in section 3.3, the average skill premium can be very insensitive to changes in the relative supply.

Second, when calibrated to fit the amounts of overeducation found in most empirical studies, the model predicts that both the relative wage and the relative employment rate of high-skill workers will depend inversely on the aggregate rate of employment. ${ }^{13}$ Induced changes in the degree of overeducation lie behind these results: an increase in aggregate employment pulls high-skill workers out of low-skill jobs and leads to a disproportionate increase in the employment rate for low-skill workers. Most empirical studies of overeducation, however, rely on surveys for a particular year and, to my knowledge, the direct evidence on induced changes of this kind is limited and inconclusive. ${ }^{14}$

It should be noted, finally, that the derivation of the non-shirking conditions assumed a steady state. The steady state assumption could be relaxed along the lines of Kimball (1994), but the analysis would then need to consider also the complications arising from different adjustment speeds for high- and low-skill employment in response to

\footnotetext{
${ }^{13}$ Even if the degree of overeducation is insufficient to reverse the sign of $d \log \frac{w_{H}}{w_{L}} / d \log n$ and ensure that low-skill workers benefit form a rise in output, both in terms of relative employment and relative wages, the presence of induced overeducation will reduce the value of $d \log \frac{w_{H}}{w_{L}} / d \log n$.

${ }^{14}$ In the UK, evidence suggests that the incidence of overeducation increased strongly between the 1970s and 1980s (a period of rising unemployment) but may have stabilized since the late 1980s (Green et al (1999)). Robinson and Manacorda (1997, p. 3) find that in the UK between 1984 and 1994 "the increase in the supply of better educated labour has allowed firms to indulge in 'credentialism', employing more highly qualified staff to do jobs which previously were done by less qualified staff". Furthermore, in the UK an index of required qualifications rose between 1986 and 1992, but then fell slightly during the period of falling unemployment from 1992 to 1997 (Green et al (2000)). In the US, the evidence is ambiguous. Wolff (2000, p. 27) concludes that between 1950 and 1990 there has been a growing mismatch "between skill requirements of the workplace and the educational attainment of the workforce, with the latter increasing much more rapidly than the former". Daly et al. (2000), on the other hand, find a decline in overeducation between 1976 and 1985. With a rapid rise in average years of schooling, however, overeducation may increasingly take the form of a discrepancy between actual and required quality of education; a focus on years of schooling will fail to register any overeducation if, for instance, MIT graduates accept jobs which otherwise could and would have been filled by graduates from less prestigious institutions.
} 
shocks. These complications associated with fluctuations in employment and differential labor hoarding become less important as the time frame is extended. Although it is illsuited in its present form for the analysis of short term fluctuations, the model may therefore be relevant for long-term changes in unemployment and wage distribution. Between the early 1970s and the early 1990s many countries, including the US and UK, witnessed increases in average unemployment, in the relative unemployment for lowskill workers and in wage inequality, both within and between groups. Many factors may have contributed to this pattern, of course, but it is consistent with the qualitative predictions of the model.

\section{Appendices}

\subsection{Appendix 1}

Using (10), (11), (13) and (16), we get

$$
\frac{w_{H}}{w_{L}}=1+\frac{e_{H H}-e_{H L}}{e_{L L}} \frac{\delta+\rho+p \frac{H}{H-N_{H}}}{\delta+\rho+p \frac{L}{L-N_{L L}}}
$$

Hence,

$$
\begin{aligned}
& d \log \frac{w_{H}}{w_{L}}=d \log \left(1+\frac{e_{H H}-e_{H L}}{e_{L L}} \frac{\delta+\rho+p \frac{H}{H-N_{H}}}{\delta+\rho+p \frac{L}{L-N_{L L}}}\right) \\
& =\frac{w_{L}}{w_{H}} \frac{e_{H H}-e_{H L}}{e_{L L}} \frac{\delta+\rho+p \frac{H}{H-N_{H}}}{\delta+\rho+p \frac{L}{L-N_{L L}}}\left(\begin{array}{c}
d \log \left(\delta+\rho+p \frac{H}{H-N_{H}}\right) \\
-d \log \left(\delta+\rho+p \frac{L}{L-N_{L L}}\right)
\end{array}\right) \\
& =\frac{w_{L}}{w_{H}} \frac{w_{H}-w_{L}}{w_{L}}\left(\begin{array}{c}
\frac{p \frac{H}{\left(H-N_{H}\right)^{2}} N_{H}}{\delta+\rho+p \frac{H}{H-N_{H}}} d \log N_{H} \\
-\frac{p \frac{L}{\left(L-N_{L L}\right)^{2}}}{\delta+\rho+p \frac{L}{L-N_{L L}}} d\left(N_{L}-N_{H L}\right)
\end{array}\right)
\end{aligned}
$$

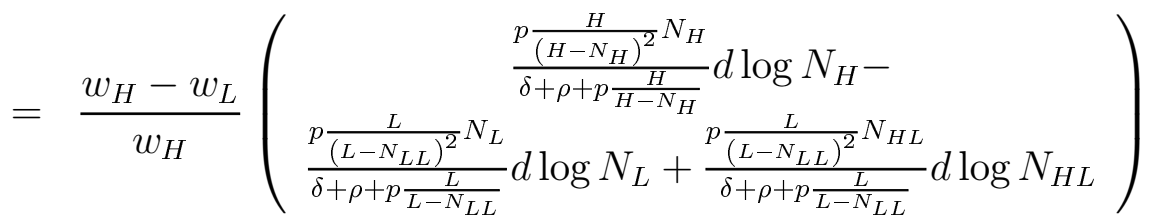

To get an expression for $d \log N_{H L}$, we combine equations (11)-(13) to get

$$
e_{H L} \frac{\delta+\rho+p \frac{H}{H-N_{H}-N_{H L}}}{\delta}=e_{L L} \frac{\delta+\rho+p \frac{L}{L-N_{L L}}}{\delta}
$$


Hence,

$$
\begin{aligned}
e_{H L} \frac{H}{H-N_{H}-N_{H L}} d \log \left(H-N_{H}-N_{H L}\right) & =e_{L L} \frac{L}{L-N_{L L}} d \log \left(L-N_{L L}\right) \\
& =e_{L L} \frac{L}{L+N_{H L}-N_{L}} d \log \left(L+N_{H L}-N_{L}\right)
\end{aligned}
$$

or

$$
\begin{aligned}
& e_{H L} \frac{H}{\left(H-N_{H}-N_{H L}\right)^{2}}\left(N_{H} d \log N_{H}+N_{H L} d \log N_{H L}\right) \\
= & e_{L L} \frac{L}{\left(L+N_{H L}-N_{L}\right)^{2}}\left(N_{L} d \log N_{L}-N_{H L} d \log N_{H L}\right)
\end{aligned}
$$

Rearranging this equation, we get

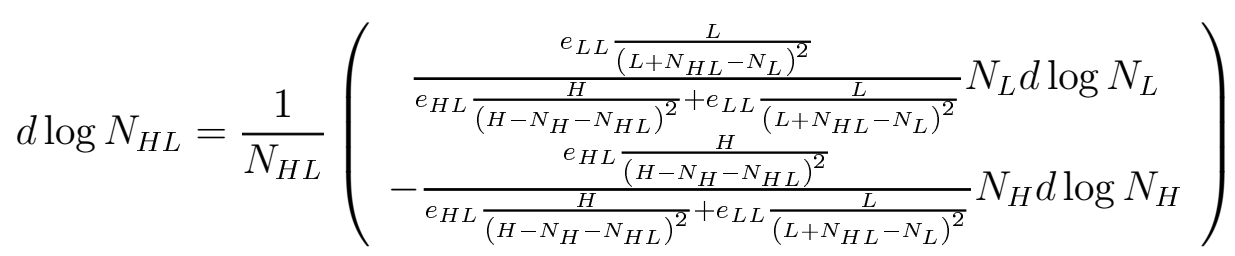

Substituting this expression into (a1) gives

$$
\begin{aligned}
d \log \frac{w_{H}}{w_{L}} & =\frac{w_{H}-w_{L}}{w_{H}} p \frac{1}{L}\left[\begin{array}{c}
\left(\frac{\frac{L}{H} x^{2}}{\delta+\rho+p x}-\frac{y^{2}}{\delta+\rho+p y} \frac{e_{H L} \frac{L}{H} z^{2}}{e_{H L} \frac{L}{H} z^{2}+e_{L L} y^{2}}\right) N_{H} d \log N_{H} \\
-\frac{y^{2}}{\delta+\rho+p y}\left(1-\frac{e_{L L} y^{2}}{e_{H L} \frac{L}{H} z^{2}+e_{L L} y^{2}}\right) N_{L} d \log N_{L}
\end{array}\right] \\
& =\frac{w_{H}-w_{L}}{w_{H}} p \frac{1}{L}\left[\frac{\frac{L}{H} x^{2}}{\delta+\rho+p x} N_{H} d \log N_{H}-\frac{y^{2}}{\delta+\rho+p y} \frac{e_{H L} \frac{L}{H} z^{2}}{e_{H L} \frac{L}{H} z^{2}+e_{L L} y^{2}} n d \log n\right] \\
& =\operatorname{En}\left[B(x) \frac{N_{H}}{n} d \log N_{H}-C(y) D(y, z) d \log n\right]
\end{aligned}
$$


where

$$
\begin{aligned}
x & =\frac{H}{H-N_{H}}=\frac{1}{u_{H}+\frac{N_{H L}}{H}} \\
y & =\frac{L}{L+N_{H L}-N_{L}}=\frac{1}{u_{L}} \\
z & =\frac{H}{H-N_{H}-N_{H L}}=\frac{1}{u_{H}} \\
E & =\frac{w_{H}-w_{L}}{w_{H}} p \frac{1}{L}>0 \text { for } e_{H H}>e_{H L} \\
B(x) & =\frac{\frac{L}{H} x^{2}}{\delta+\rho+p x}>0 \\
C(y) & =\frac{y^{2}}{\delta+\rho+p y}>0 \\
D(y, z) & =\frac{e_{H L} \frac{L}{H} z^{2}}{e_{H L} \frac{L}{H} z^{2}+e_{L L} y^{2}}>0
\end{aligned}
$$

\section{$5.2 \quad$ Appendix 2}

Profit maximization implies that

$$
d \log \frac{w_{H}}{w_{L}}=\eta\left(d \log N_{L}-d \log N_{H}\right)
$$

Using $n=N_{H}+N_{L}$ and thus $d \log n=\frac{N_{H}}{n} d \log N_{H}+\left(1-\frac{N_{H}}{n}\right) d \log N_{L}$, this equation can be rewritten

$$
d \log \frac{w_{H}}{w_{L}}=\eta \frac{n}{N_{L}}\left(d \log n-d \log N_{H}\right)
$$

Combining (a3)-(a4), we get

$$
\eta \frac{n}{N_{L}}\left(d \log n-d \log N_{H}\right)=E n\left[B(x) \frac{N_{H}}{n} d \log N_{H}-C(y) D(y, z) d \log n\right]
$$

or

$$
\frac{d \log N_{H}}{d \log n}=\frac{\frac{\eta}{N_{L}}+E C(y) D(y, z)}{\frac{\eta}{N_{L}}+E B(x) \frac{N_{H}}{n}}
$$

\subsection{Appendix 3}

Proof of proposition 1:

From (21)-(22) it follows that a general rise in economic activity will reduce wage inequality if and only if

$$
E C(y) D(y, z)>E B(x) \frac{N_{H}}{n}
$$


The value of $D(y, z)$ is decreasing as a function of the ratio $e_{H L} / e_{L L}$, and we have $D(y, z)=\frac{L}{L+H}$ for $e_{H L}=e_{L L}$. To see this, note that at an interior solution we have

$$
e_{H L}(\delta+\rho+p z)=e_{L L}(\delta+\rho+p y)
$$

and

$$
z=\frac{e_{L L}(\delta+\rho+p y)-e_{H L}(\delta+\rho)}{e_{H L} p}
$$

Hence,

$$
e_{H L} \frac{L}{H} z^{2}=\frac{L}{H} \frac{1}{p^{2}} \frac{1}{e_{H L}}\left[e_{L L}(\delta+\rho+p y)-e_{H L}(\delta+\rho)\right]^{2}
$$

For $e_{H L}=e_{L L}$ we get $z=y$ (using (a7)), and from the definition of $D(y, z)$ in combination with it follows (using (a8)) that $D$ is decreasing in $e_{H L}$ and (using (a7)) that $D(y, z)=L /(L+H)$ if $e_{H L}=e_{L L}$.

$B, C$ and $D$ are all positive and $E$ is positive when $e_{H H}>e_{H L}$. Thus, using (a6) and given the assumptions $e_{H H}>e_{H L}$ and $e_{L L}>e_{H L}$, we have the following sufficient condition for an inverse relation between the relative wage $w_{H} / w_{L}$ and aggregate employment:

$$
C(y) \frac{L}{L+H}>B(x) \frac{N_{H}}{n}
$$

or

$$
\frac{\frac{N_{H}}{H}\left(1-\frac{N_{H}}{H}\right)^{-2}}{\delta+\rho+p\left(1-\frac{N_{H}}{H}\right)^{-1}}<\frac{\frac{N_{L L}}{L}\left(1-\frac{N_{L L}}{L}\right)^{-2}}{\delta+\rho+p\left(1-\frac{N_{L L}}{L}\right)^{-1}} \frac{n}{H+L} \frac{L}{N_{L L}}
$$

The function $f(x)=x(1-x)^{-2} /\left(\delta+\rho+p(1-x)^{-1}\right)$ is increasing in $x$ for $x<1$. It follows, therefore, from (a9) that $N_{H} / H<N_{L L} / L<n /(H+L)$ is a sufficient condition for $d \log \frac{w_{H}}{w_{L}} / d \log n$ to be negative.

The second of these inequalities is always satisfied when $e_{H L}<e_{L L}$ since in this case the employment rate for high-skill workers $\left(\left(N_{H}+N_{H L}\right) / H\right)$ will exceed that for low-skill workers (cf. equation 17), and the average employment rate $(n /(H+L)$ is a weighted average of the employment rates for the two groups. The first inequality will be satisfied as long as the degree of overeducation exceeds a critical value given by $\Omega>\Omega^{\text {crit }}=\left(1-N_{L L} / L\right) /\left(1+N_{L L} / H\right)$ where $\Omega=N_{H L} /\left(N_{H}+N_{L}\right)$ is the degree of overeducation. To see this, observe that

$$
N_{H L}=\Omega\left(N_{H}+N_{L}\right)=\Omega\left(N_{H}+N_{H L}+N_{L L}\right)
$$

and

$$
(1-\Omega)\left(H-N_{H}\right) \geq(1-\Omega) N_{H L}=\Omega\left(N_{H}+N_{L L}\right)
$$


Hence,

$$
\frac{N_{H}}{H} \leq 1-\Omega\left(1+\frac{N_{L L}}{H}\right)
$$

and

$$
\frac{N_{L L}}{L}>\frac{N_{H}}{H}
$$

will be satisfied for

$$
\Omega>\frac{1-\frac{N_{L L}}{L}}{1+\frac{N_{L L}}{H}}
$$

\subsection{Appendix 4}

Proof of Proposition 2:

By definition,

$$
w_{H A}=\frac{N_{H}}{N_{H}+N_{H L}} w_{H}+\frac{N_{H L}}{N_{H}+N_{H L}} w_{L}
$$

Hence,

$$
\frac{w_{H A}}{w_{L}}=1+\frac{N_{H}}{N_{H}+N_{H L}}\left(\frac{w_{H}}{w_{L}}-1\right)
$$

and

$$
\begin{aligned}
d \log \frac{w_{H A}}{w_{L}} & =\frac{w_{L}}{w_{H A}} \frac{N_{H}}{N_{H}+N_{H L}}\left(\frac{w_{H}}{w_{L}}-1\right)\left(d \log \left(\frac{N_{H}}{N_{H}+N_{H L}}\right)+d \log \left(\frac{w_{H}}{w_{L}}-1\right)\right) \\
& =\frac{w_{L}}{w_{H A}} \frac{N_{H}}{N_{H}+N_{H L}}\left[\frac{w_{H}-w_{L}}{w_{L}}\left(\begin{array}{c}
d \log N_{H}-\frac{N_{H}}{N_{H}+N_{H L}} d \log N_{H} \\
-\frac{N_{H L}}{N_{H}+N_{H L}} d \log N_{H L}
\end{array}\right)+\frac{w_{H}}{w_{L}} d \log \frac{w_{H}}{w_{L}}\right] \\
& =\frac{w_{L}}{w_{H A}} \frac{N_{H}}{N_{H}+N_{H L}}\left[\frac{w_{H}-w_{L}}{w_{L}} \frac{N_{H L}}{N_{H}+N_{H L}}\left(d \log N_{H}-d \log N_{H L}\right)+\frac{w_{H}}{w_{L}} d \log \frac{w_{H}}{w_{L}}\right]
\end{aligned}
$$

Substituting from (a2), we get

$$
d \log \frac{w_{H A}}{w_{L}}=\frac{w_{L}}{w_{H A}} \frac{N_{H}}{N_{H}+N_{H L}}\left[\begin{array}{c}
\frac{w_{H}-w_{L}}{w_{L}} \frac{N_{H L}}{N_{H}+N_{H L}}\left(\begin{array}{c}
\left(1+D(y, z) \frac{N_{H}}{N_{H L}}\right) d \log N_{H} \\
-(1-D(y, z)) \frac{N_{L}}{N_{H L}} d \log N_{L}
\end{array}\right) \\
+\frac{w_{H}}{w_{L}} d \log \frac{w_{H}}{w_{L}}
\end{array}\right]
$$


and, using $d \log N_{L}=\frac{n}{N_{L}} d \log n-\frac{N_{H}}{N_{L}} d \log N_{H}$,

$$
\begin{aligned}
& \frac{d \log \frac{w_{H A}}{w_{L}}}{d \log n}=\frac{w_{L}}{w_{H A}} \frac{N_{H}}{N_{H}+N_{H L}}
\end{aligned}
$$

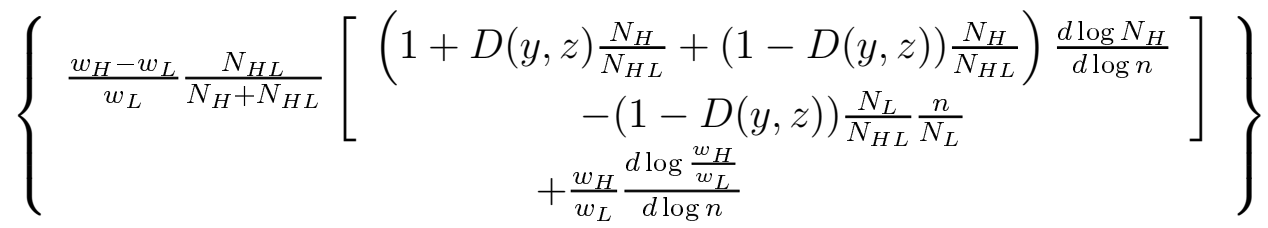

$$
\begin{aligned}
& =\frac{w_{L}}{w_{H A}} \frac{N_{H}}{N_{H}+N_{H L}}\left\{\begin{array}{c}
\frac{w_{H}-w_{L}}{w_{L}}\left[\frac{d \log N_{H}}{d \log n}-(1-D(y, z)) \frac{n}{N_{H}+N_{H L}}\right] \\
+\frac{w_{H}}{w_{L}} \frac{d \log \frac{w_{H}}{w_{L}}}{d \log n}
\end{array}\right\}
\end{aligned}
$$

The term in square brackets is positive if the conditions for $\frac{d \log \frac{w_{H}}{w_{L}}}{d \log n}$ to be negative are met. To see this, note first that $\frac{d \log N_{H}}{d \log n}>1$ when $\frac{d \log \frac{w_{H}}{w_{L}}}{d \log n}<0$. The term $D(y, z)$, second, is greater than or equal to $\frac{L}{L+H}$ (cf. Appendix 3) and hence

$$
(1-D(y, z)) \frac{n}{N_{H}+N_{H L}}<\frac{H}{L+H} \frac{n}{N_{H}+N_{H L}}<1
$$

where the last inequality follows from the fact that the overall employment rate $\left(\frac{n}{L+H}\right)$ is a weighted average of the employment rates for the two groups. Since, by assumption, the utility costs of effort are such that high-skill workers have the higher employment rate, it follows that $\frac{N_{H}+N_{H L}}{H}>\frac{n}{L+H}$.

Using (a4)-(a5) it is readily seen that $\frac{d \log \frac{w_{H}}{w_{L}}}{d \log n} \rightarrow 0$ for $\eta \rightarrow 0$. The term in square brackets on the right hand side of (a10), on the other hand is bounded above zero. It follows that $\frac{d \log \frac{w_{H A}}{w_{L}}}{d \log n}$ will be positive for sufficiently small values of $\eta$. But both $\frac{d \log N_{H}}{d \log n}$ and $\frac{d \log \frac{w_{H}}{w_{L}}}{d \log n}$ are increasing in $\eta$ - use (a4)-(a5) - and the numerical examples in section 3.2 demonstrate that, depending on parameter values and initial employment values, $\frac{d \log \frac{w_{H} A}{w_{L}}}{d \log n}$ may be either positive or negative for positive values of $\eta$.

With respect to within-group inequality we have

$$
d \sigma=\sigma\left[d \log \frac{w_{H A}-w_{L}}{w_{H A}}+0.5\left(d \log N_{H L}-d \log N_{H}\right)\right]
$$

Using equation (a2) this can be rewritten

$$
\begin{aligned}
d \sigma & =\sigma\left[d \log \frac{w_{H A}-w_{L}}{w_{H A}}+0.5\left(\frac{1}{N_{H L}}\left((1-D(y, z)) n d \log n-N_{H} d \log N_{H}\right)-d \log N_{H}\right)\right] \\
& =\sigma\left[\frac{w_{L}}{w_{H A}-w_{L}} d \log \frac{w_{H A}}{w_{L}}+0.5(1-D(y, z)) \frac{n}{N_{H L}} d \log n-0.5 \frac{N_{H}+N_{H L}}{N_{H L}} d \log N_{H}\right]
\end{aligned}
$$


Since $D \geq L /(L+H)$ and $\left(N_{H}+N_{H L}\right) / H \geq n /(L+H)$ (cf. above) we then get

$$
\frac{d \sigma}{d \log n} \leq \sigma\left[\frac{w_{L}}{w_{H A}-w_{L}} \frac{d \log \frac{w_{H A}}{w_{L}}}{d \log n}+0.5 \frac{N_{H}+N_{H L}}{N_{H L}}\left(1-\frac{d \log N_{H}}{d \log n}\right)\right]
$$

Now, $d \log N_{H} / d \log n>1$ if $d \log \left(w_{H A} / w_{L}\right) / d \log n<0$ and it follows that if betweengroup inequality is inversely related to aggregate employment, the relation between within-group inequality and employment will also be inverse.

\section{References}

[1] Borghans, L. and de Grip, A. (2000) The Overeducated Worker? The Economics of Skill Utilization, Cheltenham: Edward Elgar.

[2] Card, D., Kramarz, F. and Lemieux, T. (1999) "Changes in the Relative Structure of Wages and Employment: A Comparison of the United States, Canada and France". Canadian Journal of Economics, 32(4), pp. 843-877.

[3] Daly, M.C., Büchel, F. and Duncan, G.J. (2000) "Premiums and Penalties for Surplus and Deficit Education: Evidence from the United States and Germany". Economics of Education Review, 19 (2), pp. 169-178.

[4] Dolton, P.J. and Vignoles, A. (2000) "The Incidence and Effects of Overeducation in the UK Graduate Labour Market". Economics of Education Review, 19 (2), pp. 179-198.

[5] Green, F., McIntosh, S. and Vignoles, A. (1999) "Overeducation and Skills - Clarifying the Concepts". Centre for Economic Performance Discussion Paper 435, London School of Economics.

[6] Green, F., Felstead, A. and Gallie, D. (2000) "Computers Are Even More Important than You Thought: an Analysis of the Changing Skill-Intensity of Jobs". Centre for Economic Performance Discussion Paper 439, London School of Economics.

[7] Hartog, J. (2000) "Overeducation and Earnings: Where We Are, Where We Should Go". Economics of Education Review, 19, pp. 131-147.

[8] Hersch, J. (1991) "Education Match and Job Match". Review of Economics and Statistics, 73, pp. 140-144. 
[9] Kimball, M.S. (1994) "Labor-Market Dynamics When Unemployment Is a Worker Discipline Device". American Economic Review, 84 (4), pp. 1045-1059.

[10] Rigg, M., Elias, P., White, M. and Johnson, S (1990) An Overview of the Demand for Graduates. HMSO, London.

[11] Robinson, P. and Manacorda, M. (1997) "Qualifications and the Labour Market in Britain". Discussion Paper 330, Centre for Economic Performance, London School of Economics.

[12] Shapiro, C. and Stiglitz, J. (1984) "Equilibrium Unemployment as a Worker Discipline Device". American Economic Review, 74 (3) , pp. 433-444

[13] Sicherman, N. (1991) "Overeducation' in the Labor Market”. Journal of Labor Economics, 9, pp. 101-122..

[14] Skott, P. and Auerbach, P. (2000) "Skill asymmetries, increasing wage inequality and unemployment". Working Paper 2000-18, Department of Economics, University of Aarhus.

[15] Sloane, P.J., Battu, H. and Seaman, P.T. (1999) "Overeducation, Undereducation and the British Labour Market". Applied Economics, 31 (11), pp. 1437-1454.

[16] Thurow, L. (1998) "Wage dispersion: 'Who Done It?"'. Journal of Post Keynesian Economics, Fall, 21 (1), 25-37.

[17] Wolff, E. (2000) "Technology and the Demand for Skills". In L. Borghans and A. de Grip (eds) The Overeducated worker? The Economics of Skill Utilization, Cheltenham: Edward Elgar. 


\section{Working Paper}

2002-12: $\quad$ Morten Ø. Nielsen, Spectral Analysis of Fractionally Cointegrated Systems

2002-13: Anna Christina D'Addio and Bo E. Honoré, Duration Dependence and Timevarying Variables in Discrete Time Duration Models.

2002-14: Anna Christina D'Addio and Michael Rosholm, Labour Market Transitions of French Youth.

2002-15: Boriss Siliverstovs, Tom Engsted and Niels Haldrup, Long-run forecasting in multicointegrated systems.

2002-16: $\quad$ Morten Ørregaard Nielsen, Local Empirical Spectral Measure of Multivariate Processes with Long Range Dependence.

2002-17: $\quad$ Morten Ørregaard Nielsen, Semiparametric Estimation in Time Series Regression with Long Range Dependence

2002-18: Morten Ørregaard Nielsen, Multivariate Lagrange Multiplier Tests for Fractional Integration.

2002-19: $\quad$ Michael Svarer, Determinants of Divorce in Denmark.

2003-01: Helena Skyt Nielsen, Marianne Simonsen and Metter Verner, Does the Gap in Family-Friendly Policies Drive the Family Gap?

2003-02: Torben M. Andersen, The Macroeconomic Policy Mix in a Monetary Union with Flexible Inflation Targeting.

2003-03: Michael Svarer and Mette Verner, Do Children Stabilize Marriages?

2003-04: René Kirkegaard and Per Baltzer Overgaard, Buy-Out Prices in Online Auctions: Multi-Unit Demand.

2003-05: Peter Skott, Distributional consequences of neutral shocks to economic activity in a model with efficiency wages and overeducation. 